\begin{tabular}{cc|c}
\hline Tar. Bil. Der. & Journal of Agricultural Sciences \\
& $\begin{array}{c}\text { Dergi web sayfası: } \\
\text { www.agri.ankara.edu.tr/dergi }\end{array}$ & Journal homepage: \\
& www.agri.ankara.edu.tr/journal
\end{tabular}

\title{
Isparta İli Örneğinde CBS Yardımıyla Alternatif Turizm Etkinlikleri İçin Uygunluk Analizi
}

\author{
Mehmet TOPAY ${ }^{\text {a }}$, Makbule Özlem PARLADIR ${ }^{a}$ \\ ${ }^{a}$ Süleyman Demirel Üniversitesi, Mimarlık Fakültesi, Peyzaj Mimarlı̆̆ı Bölümü, Isparta, TÜRKIYE

\section{ESER BILLGISI} \\ Araştırma Makalesi \\ DOI: 10.1501/Tarimbil 0000001332 \\ Sorumlu Yazar: Mehmet TOPAY, E-posta: mehmettopay@sdu.edu.tr, Tel: +90 (246) 2113979 \\ Geliş Tarihi: 16 Nisan 2014, Düzeltmelerin Gelişi: 20 Haziran 2014, Kabul: 18 Temmuz 2014
}

\begin{abstract}
ÖZET
Bu çalışmada, Isparta İli’nde yapılabilecek bazı alternatif turizm etkinlikleri için ekolojik, ekonomik ve kültürel açıdan uygun alanlar, Cografi Bilgi Sistemleri (CBS) araçları kullanılarak belirlenmiştir. Bu amaca ulaşmak üzere "Uygunluk Sınıfı Değerleri” yönteminden yararlanılmıştır. Yöntem, insanların en çok tercih ettikleri bazı alternatif turizm etkinliklerinin yapılabileceği uygun alanların CBS araçları ile belirlenebilmesini sağlamaktadır ve ekolojik, ekonomik ve kültürel yapı açısından en uygun alan planlaması için belirlenen doğal ve kültürel faktörleri çizelgeler şeklinde ortaya koymaktadır. Yöntem doğrultusunda, araştırma alanına ait doğal ve kültürel özellikler belirlenmiş ve CBS programı ile sayısal veri tabanı oluşturulmuştur. Oluşturulan veri tabanı, etkinliklere ait uygunluk sınıfı değerleri çizelgelerindeki faktörlere göre sorgulanarak her bir etkinlik için en uygun alan belirlenmiştir. Bu araştırma kapsamında,en çok tercih edilen etkinliklerden atla gezinti, dağ bisikleti, dağcılık, kamping/çadırlı kamp, kayak ve trekking değerlendirmeye alınmıştır ve her etkinlik için uygunluk analizi ayrı ayrı yapılmıştır. Yapılan uygunluk analizine göre $2725 \mathrm{~km}^{2}$ lik çalışma alanınında $2580 \mathrm{~km}^{2}$ alan dağ bisikleti için, $2207 \mathrm{~km}^{2}$ alan atla gezinti için, $1721 \mathrm{~km}^{2}$ alan trekking için, 696

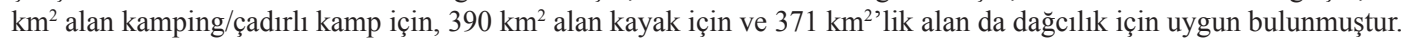
Anahtar Kelimeler: Isparta; Alternatif turizm; CBS; Alan kullanım uygunluğu
\end{abstract}

\section{GIS- Based Site Suitability Analysis for Some Alternative Tourism Activities: The Isparta Case}

\author{
ARTICLE INFO \\ Research Article \\ Corresponding Author: Mehmet TOPAY, E-mail: mehmettopay@sdu.edu.tr, Tel: +90 (246) 2113979 \\ Received: 16 April 2014, Received in Revised Form: 20 June 2014, Accepted: 18 July 2014
}

\section{ABSTRACT}

In this study, ecologically, economically and culturally suitable areas for some alternative tourism activities, which can be established in Isparta province, were determined using Geographic Information Systems (GIS) tools. In order to achieve this goal "Suitability Class Values" method was processed. This method provides GIS based determination of suitable areas for some popular alternative tourism activities and reveals natural and cultural factors determined by 
optimal spatial planning in terms of ecological, economic and cultural structure in the form of charts. In accordance with the method, natural and cultural structure of the study area was specified and a digital database was created by GIS tools. Database was examined according to the "Suitability Class Values" and suitable areas were determined for each activity. Some of the most popular activities such as horse riding, mountain biking, mountaineering, camping / tent camping, skiing and trekking were included in the assessment within the scope of this study and site suitability analysis was conducted separately for each activity. According to the suitability analysis, it was concluded that $2580 \mathrm{~km}^{2}$ area is suitable for mountain biking, $2207 \mathrm{~km}^{2}$ area is suitable for horseback riding, $1721 \mathrm{~km}^{2}$ area is suitable for trekking, 696 $\mathrm{km}^{2}$ area is suitable for camping/tent camping, and $371 \mathrm{~km}^{2}$ area is suitable for mountaineering in the total of $2725 \mathrm{~km}^{2}$ study area.

Keywords: Isparta; Alternative tourism; GIS; Land use suitability

\section{Giriş}

Turizm hareketlerindeki yoğunluğun y1lın tüm aylarına taşınması ve böylece turizmden elde edilen gelirlerin artırılmak istenmesi, turizm yatırımlarının daha verimli kullanımının sağlanmak istenmesi gibi gerekçeler alternatif turizm seçeneklerini gündeme getirmektedir (Butler 1990; Fennel 1999; McGehee 2002). Alternatif turizm, doğal kaynak stoklarını koruyarak kaliteli bir çevre oluşturmayı ve yöre halkının turizm ile ilgili aktivitelerini kontrol ederek bu yönde ekonomik fayda sağlamayı amaçlamaktadır. $\mathrm{Bu}$ nedenle sürdürülebilir gelişimin temelleri ile alternatif turizm kavramları arasında yakın bir ilișki bulunmaktadır (Pearce 1992; Dowling 1993; Durgun 2006).

1980'li yılların sonunda, çevre boyutu göz önüne alınmazsa, turizm yörelerinin çekiciliğinin azalacağı, hatta yok olacağı anlaşılmıştır. 1980'li yılların sonlarında, Türkiye'de Dünya ile birlikte hareket ederek turizm kalıplarında değişiklikler yapmış ve alternatif turizm türlerine yönelmeye başlamıştır (Doğaner 1994).Turizm Bakanlığı’nın turizmi çeşitlendirmek ve yaygınlaştırmak amacıyla yaptığı alternatif turizm çalışmaları, 1990'lı yıllarda başlamıştır. $\mathrm{Bu}$ çalışmalarda, özellikle ülkemiz kırsal alanlarında rahat bir şekilde gerçekleştirilecek yayla turizmi, doğa yürüyüşü (trekking), kış turizmi ve termal turizm gibi birkaç etkinlik üzerinde durulmuştur (TBYGM 2004).

Sürdürülebilirliğin gerçekleştirilebilmesi ve dünya turizm hareketliliği içinde ülkenin bir destinasyon olarak sahip olduğu yerin daha üst sıralara taşınabilmesi amacıyla Kültür ve Turizm Bakanlığ1 tarafından Türkiye Turizm Stratejisi 2023 Eylem Planı uygulamaya konulmuştur. Planda, ülkemizin kıyı turizmi yanı sıra, alternatif turizm (sağlık ve termal turizm, kış sporları, dağ ve doğa turizmi, yayla turizmi, kırsal ve eko turizm, kongre ve fuar turizmi, kruvaziyer ve yat turizmi, golf turizmi, v.b.) gibi turizm türleri açısından da eşsiz imkanlara sahip bulunduğu bildirilmekte, bununla birlikte, bu potansiyelin rasyonel anlamda kullanılamadığına değinilmektedir. Türkiye Turizm Stratejisi 2023 ve Eylem Planı 2013'te, "ülkemizin doğal, kültürel, tarihi ve coğrafi değerlerini koruma-kullanma dengesi içinde kullanmayı ve turizm alternatiflerini geliştirerek ülkemizin turizmden alacağı payı arttırmayı hedef almaktadır" denilmektedir (KTB 2014). Ülkemiz turizminin geleceği ile ilgili bu planlı gelişim hedeflerinin, alternatif türlerin geliştirilmesi yönünde olduğu ve bu kapsamda yapılacak çalışmaları açıkça ifade ettiği görülmektedir.

Isparta ili de alternatif turizm türleri bakımından önemli bir potansiyele sahiptir ve bir çok çalışmada bölgenin kalkınmasında turizmin özellikle de alternatif turim türlerinin önemi vurgulanmıştır (Yeşiltaş \& Öztürk 2008; Korkmaz \& Başkalkan 2011; Türkoğlu et al 2005; Doğan \& Üngüren 2012, Parladir 2013).

Araştırmanın amac1, Isparta ilinde gerçekleştirilebilecek ve insanların yapmayı en çok tercih ettiği at ile gezinti, dağ bisikleti, dağcılık, kamping/çadırlı kamp, kayak ve trekking etkinliği 


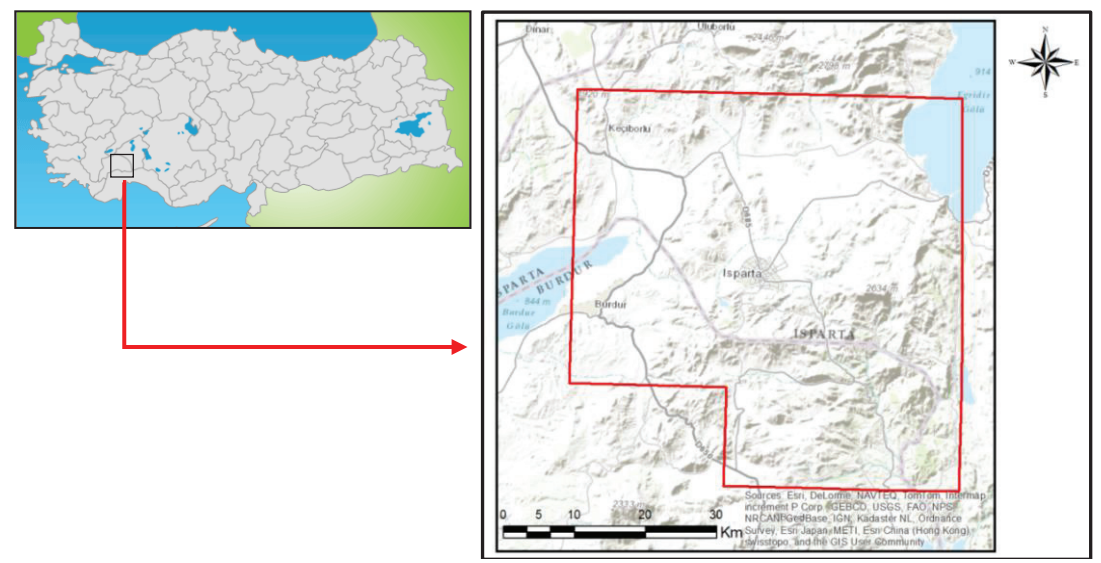

Şekil 1- Çalışma alanının Türkiye içindeki konumu ve sınırları

Figure 1-Location and boundries of study area in Turkey

(Ryan 1991, Gunn 1994) için uygun olan bölgeleri CBS araçları yardımı ile geniş ölçekte ve hassas bir şekilde belirlemek ve böylece Isparta ilinin turizm stratejilerinin belirlenmesinde yol gösterici olacak ve ekolojik, ekonomik ve kültürel temellere dayandırılmış haritalar oluşturmaktır.

\section{Materyal ve Yöntem}

Araştırmanın ana materyalini, Isparta ili sınırları içinde yer alan ve Şekil 1'de kırmızı çizgiler ile verilen ve bazı alternatif turizm etkinliklerinin gerçekleştirilmesi açısından uygun doğal ve kültürel özelliklere sahip olan bölge oluşturmaktadır. Çalışma alanının yüzölçümü $2725 \mathrm{~km}^{2}$ dir ve 1/25000 ölçekli 18 paftayı içermektedir. Alan sınırı, Isparta kent merkezi odak noktası kabul edilerek kent merkezinden araçla günübirlik ulaşım mesafesine göre (yerel halkın günübirlik turizmrekreasyon amaçlı gittiği mesafe çoğunlukla yaklaşık 50 km'dir) belirlenmiştir.

Araştırma kapsamında yararlanılan ve Topay (2003) tarafindan ekolojik, ekonomik ve kültürel faktörlere göre geliştirilen yöntem, bazı alternatif tuizm etkinliklerini gerçekleştirebilmek için gerekli alan seçiminde dikkate alınması gereken 1 . ve 2 . derecedeki doğal ve kültürel değerlendirme faktörleri ile bu faktörlere ait değer aralıklarını çizelgeler halinde sunmaktadır. Çizelgelerin oluşturulmasında o etkinliği yapan deneyimli kişiler ile görüşülmüş ve elde edilen uzman görüşleri doğrultusunda faktörler ve bu faktörlere ait öncelik sırası ve değer aralıkları belirlenmiştir. Araştırma kapsamında insanların en çok yapmayı tercih ettikleri ve alanın doğal ve kültürel özellikleri dikkate alındığında yapılması uygun olabilecek altı etkinlik seçilmiştir. Bunlar; at ile gezinti, dağ bisikleti, dağcılık, kamping/çadırlı kamp, kayak ve trekkingdir. Ele alınan 6 etkinliğe ait "Uygunluk Sınıfı Değerleri" çizelgesinin daha iyi anlaşılabilmesi için yalnızca "At ile Gezinti" etkinliğine ait değerlendirme faktörleri ve bu faktörlere ait değer aralıkları Çizelge 1'de örnek olarak verilmiştir.

Çalışmada, öncelikle sınırları belirlenen alanlar içindeki doğal ve kültürel yapı araştırılmış ve veriler CBS araçları kullanılarak sayısal veri tabanına aktarılmıştır. Mekansal planlama sürecinde çalışılan alana ait doğal ve kültürel verilerin etkili bir şekilde belirlenmesi, depolanmasi, analiz edilmesi, yeni verilerin elde edilmesi, yönetimi ve sunulması gibi karmaşık ve özen isteyen bir sürecin yürütülmesinde yardımcı olacak araçlardan birisi Coğrafi Bilgi Sistemleri (CBS) içinde yer alan yazılımlardır (Collins et al 2001; Topay 2002; Malczewski 2004; 2006) ve CBS araçları karar verme sürecini etkin bir şekilde desteklemekte ve uygunluk analizlerinin yapılmasını oldukça kolaylaştırmakta (Cengiz et al 
Çizelge1- "At ile gezinti” için değerlendirme faktörleri (Topay 2003; Topay \& Memlük 2011)

Table 1- Evaluation criteria for "Horseback Riding” (Topay 2003; Topay \& Memlük 2011)

\begin{tabular}{|c|c|c|c|c|c|}
\hline \multicolumn{6}{|c|}{ At ile Gezinti Etkinliği } \\
\hline \multirow{2}{*}{\multicolumn{4}{|c|}{ Değerlendirme Faktörleri }} & \multicolumn{2}{|c|}{ Uygunluk Sinıfi Değerleri } \\
\hline & & & & $A 1$ & \\
\hline \multirow{15}{*}{ 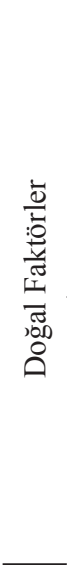 } & & 1 & Eğim durumu (\%) & $0-30$ & $30+$ \\
\hline & & 2 & Heyelan durumu & Küçük Ölçüde & - \\
\hline & & 3 & Taban suyu düzeyi (m) & $2 \mathrm{~m}+$ & - \\
\hline & $\circ$. & 4 & Toprak drenaji & İyi & Orta \\
\hline & - & 5 & Ortalama rüzgar hızı $\left(\mathrm{msn}^{-1}\right)$ & $0-4$ & $4-8$ \\
\hline & & 6 & Bağıl nem durumu (\%) & $40-80$ & $20-40$ \\
\hline & & 7 & Fauna için hassas alanlar-zonlar & Yok & - \\
\hline & & 8 & Flora için hassas alanlar-zonlar & Yok & - \\
\hline & & 1 & Bulutluluk ve güneşlenme $(\mathrm{X} / 10)$ & $0-8$ & $8-10$ \\
\hline & & 2 & Y1llı ortalama sicaklık $\left(\mathrm{C}^{\circ}\right)$ & $10-20$ & $20-38$ \\
\hline & & 3 & Mikroklima varlı̆̆ı & Var & - \\
\hline & $i$ & 4 & Yıllık yağış ortalaması $(\mathrm{mm})$ & $250-1250$ & $0-250 ; 1500+$ \\
\hline & & 5 & Su kaynağı varlı̆̆ı (m) & $300-1600$ & $1600+$ \\
\hline & & 6 & Su varlığının kalitesi & Sinif I & Sinif II \\
\hline & & 7 & Şimdiki alan kullanımı & T,F,P,M,Ç,O & - \\
\hline \multirow{5}{*}{ 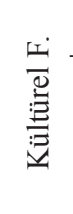 } & $\stackrel{\circ}{-}$ & 1 & İnsan ilişkileri & Olumlu & - \\
\hline & & 1 & Ulaşım mesafesi (m) & $0-3000$ & $3000+$ \\
\hline & $\stackrel{\circ}{i}$ & 2 & Haberleşme olanakları (m) & $0-3000$ & $3000+$ \\
\hline & N & 3 & Konaklama-barınma olanakları & İyi & Orta \\
\hline & & 4 & Sağlık tesisi varlı̆̆ $(\mathrm{m})$ & $0-3000$ & $3000+$ \\
\hline
\end{tabular}

2013), planlama sürecinde etkili olan parametrelere göre geliştirilen modellerin çalıştırılması ve bu yolla geleceğe dair projeksiyonların yapılmasını olanaklı kılmaktadır (Topay 2007). Çalışmada CBS yazılımlarından Arc GIS 10.1 kullanılmıştır.

Araştırma alanı, her bir etkinlik için hazırlanan çizelgelerdeki değerlendirme faktörlerine ait değerler göz önüne alınarak sorgulanmıştır. Sorgulama sürecinde çok kriterli seçim sürecinde önemli kolaylıklar sağlayan "Model Builder" uzantısından yararlanılarak etkinlikler için en uygun alanlar belirlenmiş ve haritalandırılmıştır. Etkinlik için değerlendirmeye alınan doğal ve kültürel faktör sayısı $35^{\prime}$ tir ve etkinlikler için değerlendirme faktörleri aşağıda sıralanmıştır: Dağ bisikleti; Doğal Faktörler (1..$^{\circ}$ ): Heyelan durumu, taban suyu düzeyi, fauna için hassas alanlar-zonlar, flora için hassas alanlar-zonlar. $\left(2 .^{\circ}\right)$ : Çığ riski, su kaynağı varlığı, su varlığının kalitesi, taşkın alanı varlığı, ortalama rüzgar hızı, bağıl nem durumu, yıllık yağı̧̧ ortalaması, yıllık sıcaklık ortalaması, toprak drenaj1, jeolojik jeomorfolojik oluşumların varlığ 1 , endemik bitki türü varlığı, şimdiki alan kullanımı. Kültürel Faktörler (1. $\left.{ }^{\circ}\right)$ : İnsan ilişkileri. $\left(2 .^{\circ}\right)$ : Konaklama barınma olanakları, haberleşme olanakları, sağlık tesisi varlığı. Dağcılık; Doğal Faktörler (1. $\left.{ }^{\circ}\right)$ : Eğim, heyelan durumu, çığ riski, ortalama rüzgar hızı, fauna için hassas alanlarzonlar, flora için hassas alanlar-zonlar. $\left(2{ }^{\circ}\right)$ : Bulutluluk ve güneşlenme oranı, yükseklik grupları, jeolojik jeomorfolojik oluşumların varlığı, endemik bitki türü varlığı, şimdiki alan kullanımı. Kültürel Faktörler (1. $\left.{ }^{\circ}\right)$ : İnsan ilişkileri. $\left(2 .^{\circ}\right)$ : Konaklama barınma olanakları, haberleşme olanakları, ulaşım mesafesi, sağlık tesisi varlığı. Kamping/çadırlı kamp; Doğal Faktörler (1. $\left.{ }^{\circ}\right)$ : Eğim, çı̆̆ riski, heyelan durumu, su kaynağı 
varlığı, su varlığının kalitesi, toprak drenajı, toprak tekstürü, taban suyu düzeyi, fauna için hassas alanlar-zonlar, flora için hassas alanlar-zonlar. $\left(2 .^{\circ}\right)$ : Yükseklik grupları, bakı, ortalama rüzgar hızı, şimdiki alan kullanımı,bağıl nem durumu, jeolojik jeomorfolojik oluşumların varlığı,endemik bitki türü varlığı, taşkın alanı varlığı. Kültürel Faktörler $\left(1 .^{\circ}\right)$ : İnsan ilişkileri, gürültü. $\left(2 .^{\circ}\right)$ : Haberleşme olanakları, elektrik kaynağ 1 varlığ 1 , sağlık tesisi varlığı, ulaşım mesafesi. Kayak; Doğal Faktörler $\left(1 .^{\circ}\right)$ : Bak1, eğim, karla örtülü gün sayısı, kar kalınlığı, karın niteliği, çı̆̆ riski, fauna için hassas alanlar-zonlar, flora için hassas alanlarzonlar. (2..$^{\circ}$ ): Ortalama rüzgar hızı, bulutluluk ve güneşlenme, yükseklik grupları, rüzgar yönü, bağıl nem durumu, jeolojik jeomorfolojik oluşumların varlığı, şimdiki alan kullanımı, su kaynağ 1 varlığ 1 , doğal bitki varlığ 1 . Kültürel Faktörler $\left(1 .^{\circ}\right)$ : İnsan ilişkileri, gürültü. $\left(2 .^{\circ}\right)$ : Konaklama barınma olanakları, haberleşme olanakları, sağlık tesisi varlığı, ulaşım mesafesi. Trekking; Doğal Faktörler $\left(1 .^{\circ}\right)$ : Heyelan durumu, çığ riski, ortalama rüzgar hızı, bağıl nem durumu, fauna için hassas alanlarzonlar, flora için hassas alanlar-zonlar. (2..$\left.^{\circ}\right)$ : Eğim, bulutluluk ve güneşlenme, su varlığının kalitesi, su kaynağ 1 varlığ 1 , doğal hayvan varlığ 1 , endemik hayvan türlerinin varlığ 1 , şimdiki alan kullanımı. Kültürel Faktörler (1. $\left.{ }^{\circ}\right)$ : İnsan ilişkileri. $\left(2 .^{\circ}\right)$ : Konaklama barınma olanakları, haberleşme olanakları, sağlık tesisi varlığı, ulaşım mesafesi.

\section{Bulgular ve Tartışma}

\subsection{Doğal yapr}

Çalışma alanı içindeki yükseklik değerleri 290 $\mathrm{m}$ ile $2635 \mathrm{~m}$ arasında değişim göstermektedir.
Alanın en yüksek bölümü kent merkezinin güneyinde kalan dağ sistemidir. En yüksek noktası ise Davraz Dağı zirveleridir $(2635 \mathrm{~m})$. Eğim grupları düzden başlayarak 90 dereceye kadar değişim göstermektedir. En fazla eğim, Davraz Dağı'nın da yer aldığı ve kent merkezinin güney doğusunda kalan dağ sisteminin olduğu bölgelerde bulunmaktadır. Ovanın yer aldığı bölgeler ise düz ve düze yakın eğimin görüldüğü alanlardır. Alanda baskın olan eğim grubu 0-25 derece arasındadır ve her yöne bakan yamaçlar bulunmaktadır. Şekil 2'de yükseklik, eğim, bakı grupları ve çalışma alanı içinde yer alan farklı boyutlarda yüzey suları (akarsu, göl, gölet, baraj, vb.) haritaları sunulmuştur. İl arazilerini başlıca üç jeomorfolojik ana birime ayırmak mümkündür. $\mathrm{Bu}$ ana birimlerden biri; Isparta ilinin çevresini doğal bir sınır gibi çevreleyen dağlık alanlar, bir diğeri yörede yer alan ovalar ve son olarak da ovalarla dağlar arasında kalan az eğimli, dalgalı arazilerden oluşan plato sahalarıdır ve bazı yerleşim alanlarında heyelan potansiyeli bulunmaktadır (ÇŞB 2014).

Çalışma alanı içinde en sicak ay temmuz, en soğuk ay ise ocaktır. En nemli ay ocak, en az nemli ay ise ağustostur. Yıllık yağış ortalaması en yüksek olan ay aralık, en az yağışlı ay ise ağustostur. Hakim rüzgar yönü ağırlıklı olarak GB ve G'dir. Rüzgar hızı en yüksek nisanda, en düşük kasımdadır (Çizelge 2). Çalışma alanında genel hayatı etkileyecek bir çı̆̆ afeti bilgisine ulaşılmamıştır (ÇŞB 2014). Dolayısıyla, çalışma alanı bütününde çı̆̆ riski yok sayılmıştır. Alan sınırları içinde mikroklimatik bir oluşumun varlığ bilgisine ulaşılmamıştır.

Çizelge 2- Isparta ili ortalama iklim değerleri (1960 - 2012) (MBM 2014)

Table 2- Mean climatic values of Isparta province (1960 - 2012) (MBM 2014)

\begin{tabular}{|c|c|c|c|c|c|c|c|c|c|c|c|c|}
\hline Aylar & $O$. & Ş. & M. & $N$. & M. & $H$. & $T$. & A. & $E$. & $E$. & $K$. & A. \\
\hline Sicaklık $\left({ }^{\circ} \mathrm{C}\right)$ & 1.9 & 2.8 & 6.1 & 10.7 & 15.6 & 20.2 & 23.6 & 23.2 & 18.6 & 13.0 & 7.4 & 3.5 \\
\hline Nem (\%) & 79 & 76 & 70 & 70 & 68 & 59 & 44 & 40 & 43 & 59 & 55 & 68 \\
\hline YağıIș $\left(\mathrm{kg} \mathrm{m}^{-2}\right)$ & 72.7 & 64.8 & 54.3 & 56.1 & 50.1 & 29.5 & 13.5 & 10.5 & 15.6 & 36.4 & 46.1 & 85.6 \\
\hline Hak. Rüzgar Yön. & GB & GB & G & G & G & B & GB & G & B & GB & GB & $\mathrm{KB}$ \\
\hline Rüz. Hızı (m s$\left.{ }^{-1}\right)$ & 1.6 & 1.7 & 1.9 & 2.2 & 2.0 & 1.9 & 1.9 & 1.9 & 1.7 & 1.8 & 1.4 & 1.8 \\
\hline
\end{tabular}




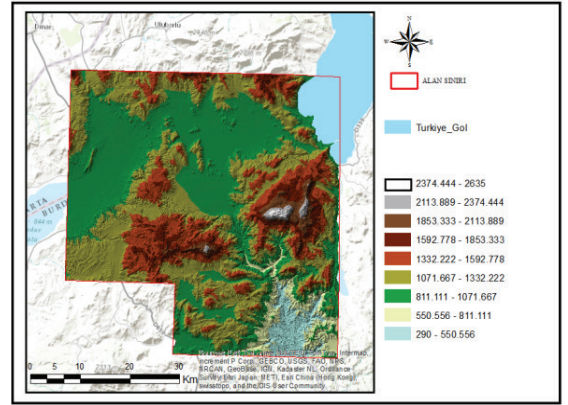

$\mathbf{a}$

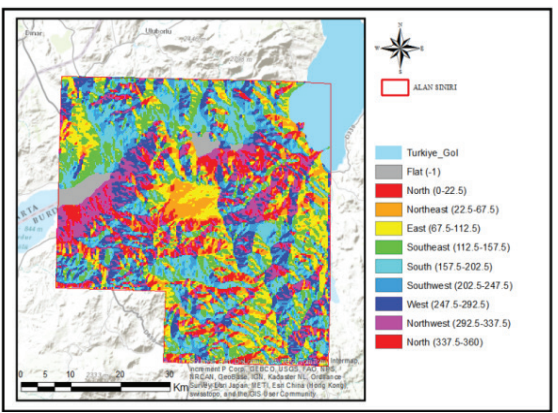

c

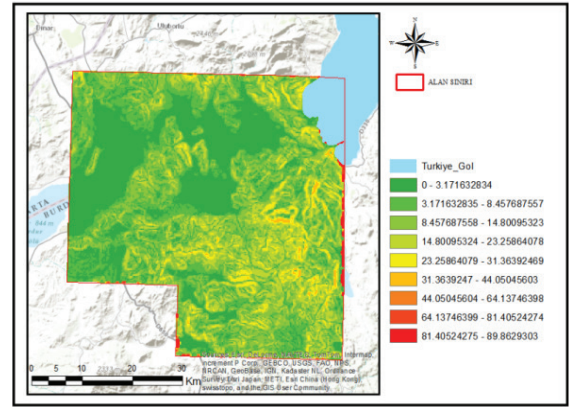

b

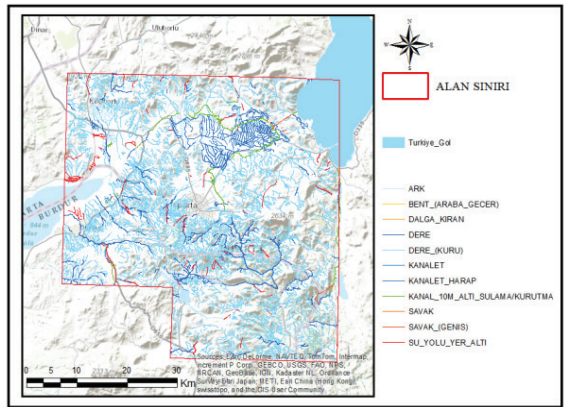

d

Şekil 2- Yükseklik (a), eğim (b), bakı grupları (c) ve hidroloji (d) haritaları

Figure 2-Maps of altitude (a), slope (b), aspect groups (c) and hydrology (d)

Çalışma alanı içindeki yaban hayatı ve doğal bitki varlığg zengin bir yapı sergilemektedir (ÇŞB 2014). Çalışma alanı içinde mevcut olan odunsu bitki varlığnın alansal dağılımını gösteren harita Şekil 3’te verilmiştir.

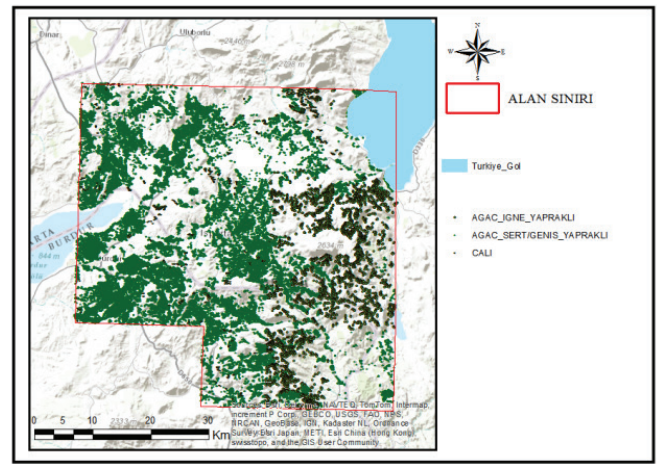

Şekil 3- Çalışma alanının odunsu doğal bitki varlığı haritası

Figure 3-Vegetation maps of study area

\subsection{Kültürel faktörler}

Çalışma alanında işletme ve yatırım belgeli 13 otel, belediye belgeli 34 adet otel ve belediye belgeli 21 pansiyon bulunmakta olup toplam yatak kapasitesi 3841 adettir. Haberleşme ve elektrik altyapısı olmayan yerleşim birimi yoktur. İl sağlık hizmetleri açısından önemli bir düzeydedir. Son yıllarda özel hastanelerin de artmasıyla birlikte Isparta, bölgesel bir tıp merkezi konumundadır (ÇŞB 2014). Çalışma alanında insanları rahatsız edecek düzeyde bir gürültü kaynağı bulunmamaktadır. Alanda yaşayan halkın turizm etkinliklerine bakış açısı son derece olumlu olarak belirlenmiştir (sözlü görüşme). Çalışma alanı içinde ulaşımı sağlayan yol ağı Şekil 4'te verilmiştir.

Araştırmada, alternatif turizm etkinlikleri kapsamında altı adet etkinlik ele alınmış, her bir etkinlik için Isparta ili özelinde "en uygun" alanlar belirlenmiştir. Etkinlikler için en uygun alanların 


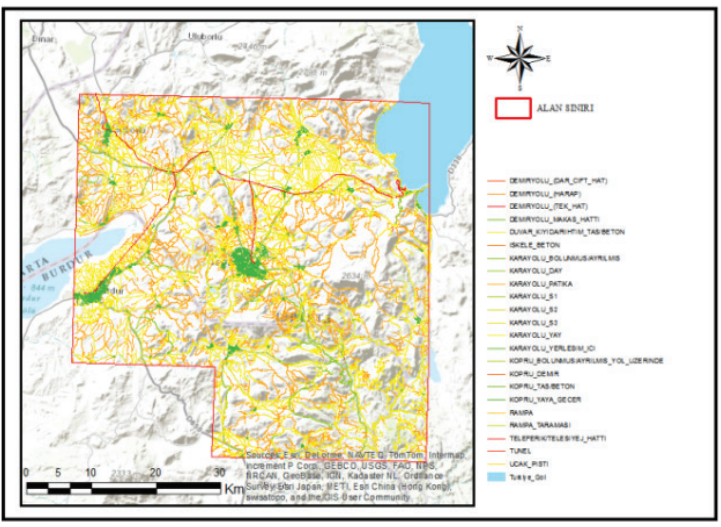

Şekil 4- Çalışma alanının ulaşım ağı haritası

Figure 4- Transportation network maps of study area belirlenmesinde yararlanılan ve CBS araçları içinde sorgulama sürecini kısaltarak sağ liklı bir hale getiren "Model Builder" uzantısından yararlanılmıștır. Araştırma alanı içinde yer verilen etkinliklere ait alan seçim kriterleri doğrultusunda geliştirilen modeller ve bu modellerin çalıştırılması sonucunda her bir etkinlik için elde edilen alanlar Şekil 5'te yer alan haritalarda gösterilmiştir.

At ile gezinti etkinliği için değerlendirmeye alınan doğal ve kültürel faktör sayısı 20'dir. Etkinlik için oluşturulan modelin çalıştırılması sonucunda uygun bulunan alanlar $2207 \mathrm{~km}^{2}$ olup çalışma alanının büyük bir bölümünü kapsamaktadır. Dağ bisikleti etkinliği için uygun alanlar $2580 \mathrm{~km}^{2}$ olup, atla gezinti etkinliği gibi alanın neredeyse bütününde

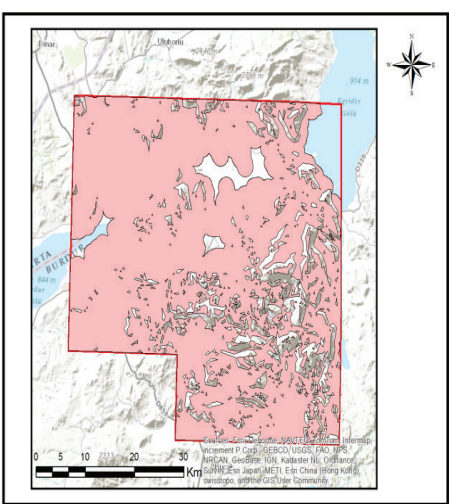

$\mathbf{a}$

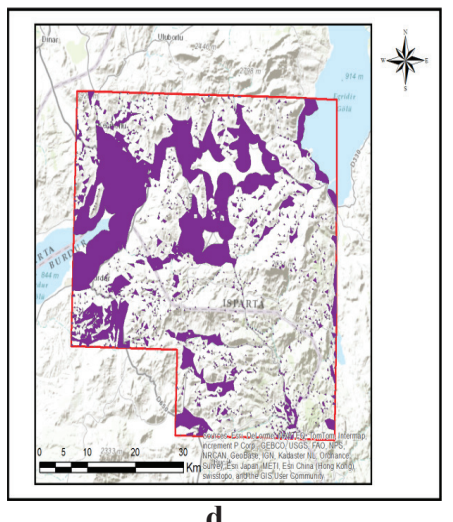

d

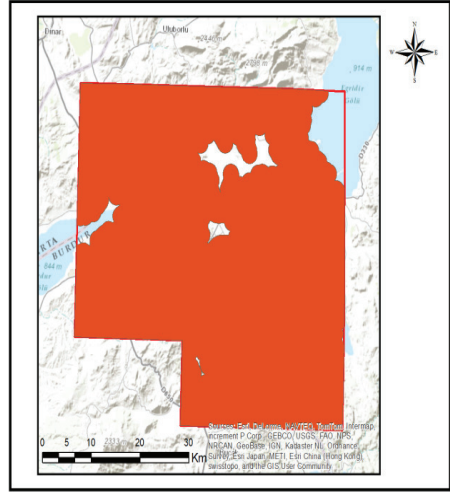

b

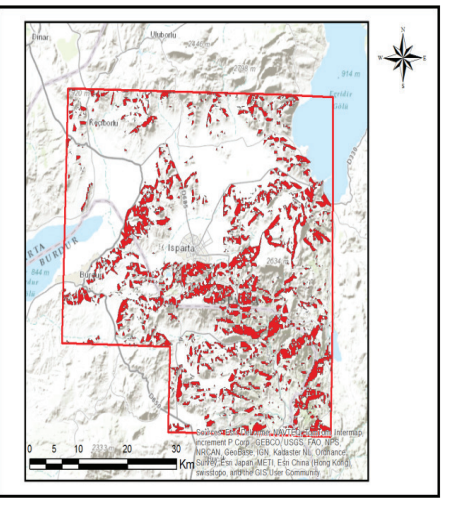

e

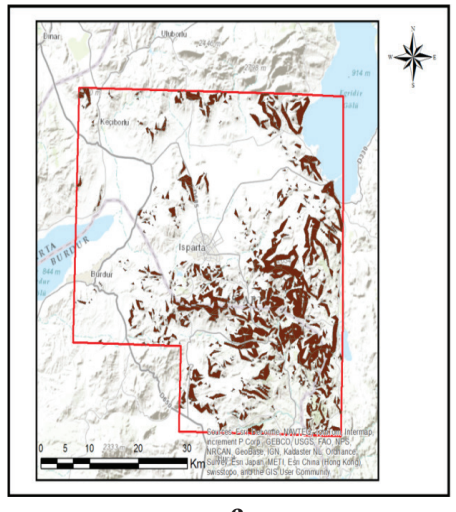

c

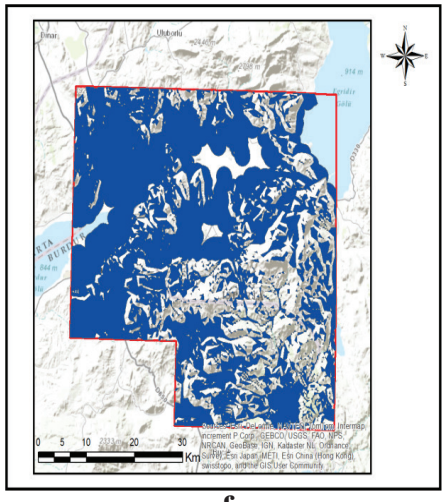

f

Şekil 5- Etkinlikler için uygun alanlar. a) At ile gezinti b) Dağ bisikleti c) Dağcılık d) Kamping / Çadırlı kamp e) Kayak f) Trekking

Figure 5- Sutable areas for avtivities. a) Horse riding b) Mountain bike c) Mountaineering d) Camping / Tent camping e) Skiing f)Trekking 
gerçekleştirilebilmektedir. Dağcılık etkinliği için uygun alanlar $371 \mathrm{~km}^{2}$ olup çalışma bölgesinin genel olarak hareketli yapı sergilediği güney doğu bölümünde yoğunlaşmaktadır. Bu etkinliğe uygun olan alanların belirlenmesinde "eğim" en belirleyici kriter olarak karşımıza çıkmıştır.

Kamping/çadırlı kamp etkinliği için uygun alanlar $696 \mathrm{~km}^{2}$ olup çalışma alanının daha çok kuzey ve batı bölümlerinde yoğunlaşmıştır. Etkinlik için uygun alanların bu bölümlerde yoğunluk kazanmasının temel nedeni düz ve düze yakın bölgelerin bu kısımlarda yer almasıdır. Kayak etkinliği için uygun alanlar $390 \mathrm{~km}^{2}$ olup alanda genellikle dağlık bölgelerde dağılış göstermektedir. $\mathrm{Bu}$ etkinlik için uygun alanların belirlenmesinde etkin unsur "bakı"dır. Çalışma alanının büyük bir bölümü trekking için uygun alanlar olarak karşımıza çıkmaktadır $\left(1721 \mathrm{~km}^{2}\right)$. Sadece eğimin fazla olduğu bazı bölgeler trekking açısından uygun olmayan bölgelerdir.

Alternatif turizm, dünya genelinde giderek artan bir şekilde yaygınlık kazanmaktadır. Dünyada yaşanan yeni eğilimler ve doğal sistemler üzerindeki kirlenmeler, turizmde yeni yönelimlerin ortaya çıkmasında önemli bir etken teşkil etmektedir. Sosyal ve iş yaşamındaki tekdüzelik de alternatif turizm faaliyetlerine olan talebi artırmaktadır. Alternatif turizm ve yeni turistik ürünler bu nedenle önemini artırmıştır. Turizmin yöreler için sürdürülebilirliği açısından bu kavramlar son derece önemlidir. Isparta ili turizminin önemli merkezlerinden birisi olmak için alternatif turizm açısından yeterli potansiyele sahip bir il konumunda bulunmaktadır.

Isparta ilinin alternatif turizm potansiyelinin değerlendirilmesine ve bu potansiyelin bölge turizmine olan etkisini incelemeye yönelik yapılan çalışmanın uygulama aşaması sonuçlarını değerlendirdiğimizde; Isparta ilinin at ile gezinti, dağ bisikleti, dağcılık, kamping/çadır kampı, kayak ve trekking etkinlikleri için uygun olduğu görülmektedir.Ancak yapılan araştırma sonuçlarına göre bölgenin turizme kazandırılamamasındaki başlıca sıkıntı yeterince tanıtımın yapılamamasıdır (Türkoğlu et al 2005; Doğan \& Üngüren 2012;
Korkmaz \& Başkalkan 2011). Bu bağlamda turizm pazarından pay alabilmek ve sahip olunan pay oranını artırmak için etkin ve etkili bir tanıtım politikası izlenmeli, yazılı ve sözlü basın araçlarından yararlanılmalı, bölgenin sahip olduğu tabii güzellikler kullanılmalı ve alternatif turizm etkinliklerinden atla gezinti, dağ bisikleti, dağcılık, kamping/çadır kampı, kayak ve trekking gibi etkinliklerin yanı sıra diğer etkinlikler için de tanıtım çalışmalarında bulunulmalıdır.

Araştırma kapsamında yerel halk ve idarecilerle yapılan doğrudan ve dolaylı görüşmelerde, gerek yerel halkın gerekse yerel idarecilerin bölgenin kalkındırılabilmesi amacıyla farklı arayışlar içinde olduğu ve bu arayış doğrultusunda rekreasyonturizm etkinliklerinin önemli birer araç olarak alanda yer alması gerektiği inancını taşıdıkları görülmüştür. $\mathrm{Bu}$ belirlemeler 1şığında, Isparta ili sınırları içinde en kısa zamanda bir planlama çalışmasının gündeme getirilmesine ihtiyaç duyulduğu belirlenmiştir. Yürütülecek böylesi bir planlama çalışması ile hem yerel halkın ekonomik anlamda kalkınma beklentilerine cevap verilebilecek, hem kaynakların sürdürülebilir kullanımı adına önemli bir adım atılabilecek hem de bölgede görülen rekreasyon-turizm ihtiyacının giderilmesine katk1 sağlanabilecektir.

\section{Sonuçlar}

Tüm dünyada yaşanan ekonomik, çevresel, sosyal değişimler dikkate alındığında, kırsal nitelikli alanlardaki tek yönlü kullanımların rekreasyonturizm etkinlikleri ile çeşitlendirilmesinin gerek yerel ekonomi, gerek kaynakların akılcı ve sürdürülebilir kullanımı ve gerekse toplum sağlığına etkilerinin büyük olacağ 1 giderek daha geniş kitleler tarafından kabul görmektedir. Buna bağlı olarak, alana uygun kullanım tiplerinin belirlenmesine yönelik çalışmalar giderek artmakta ve farklı analiz teknikleri ile planlama yaklaşımları gündeme gelmektedir (Topay 2003).

$\mathrm{Bu}$ konuda, dünyada yaşanan olumlu gelişmelerin başta topografya, doğal bitki varlığ ve doğal hayvan varlığı olmak üzere doğal kaynak 
Doğan H \& Üngüren E (2012). Yerel halkın 1sparta turizmine yönelik görüşleri üzerine bir araştırma. SDÜ İktisadi ve Ídari Bilimler Fakültesi Dergisi 17(1): 103-122

Doğaner Y (1994). Köyceğiz-Dalyan Çevresinde EkoTurizm. Türkiye Kalkınma Bankası Turizm Yıllığ1

Dowling R K (1993). An environmentally based approach to tourism planning. PhD Thesis, School of Biological and Enviromental Sciences, Murdoch University, (Unpublished), Western Australia

Durgun A (2006). Bölgesel kalkınmada turizmin rolü. Yüksek Lisans Tezi, Süleyman Demirel Üniversitesi Sosyal Bilimler Enstitüsü (Basılmamış), Isparta

Fennel D (1999). Ecotourism an Introduction. Taylor \& Francis Group

Gunn C (1994). Tourism Planning, Basic, Concept, Cases. Publishing Office: Taylor \& Francis, USA

Korkmaz M \& Başkalkan S N (2011). Eğirdir Gölü ve çevresinde turizm gelişiminin sürdürülebilirliği üzerine değerlendirmeler. SDÜ Orman Fakültesi Dergisi 12: 62-69

KTB (2014). Türkiye Turizm Stratejisi 2023. http:/teftis. kulturturizm.gov.tr/TR,14577/ turkiye-turizm-stratejisive-eylem-plani.html (Erişim tarihi: 13.04.2014)

Malczewski J (2004). GIS-based land use suitability analysis: a critical over view. Progress in Planning 62(1): 3-65

Malczewski J (2006). GIS-based multicriteria decision analysis: asurvey of theliterature. International Journal of Geographical Information Science 20(7): 703-726

MBM (2014). T.C. Orman ve Su İşleri Bakanlığ Meteoroloji Bölge Müdürlüğü. http://www.mgm. gov.tr/ veridegerlendirme/ il-ve-ilceler-istatistik. aspx?m=ISPARTA (Erişim Tarihi: 14.04.2014)

McGehee N G (2002). Alternative tourism and social movements. Annals of Tourism Research 29(1): 124143
Parladır M Ö (2013). Isparta ili'nde yapılacak alternatif turizm türlerinin ve yerlerinin CBS araçları ile belirlenmesi. Yüksek Lisans Tezi, Süleyman Demirel Üniversitesi, Fen Bilimleri Enstitüsü (Basılmamış), Isparta

Pearce D G (1992). Alternative Tourism: Concept, Classification, and Questions. Tourism Alternatives, International Academy for the Study of Tourism, USA

Ryan C (1991). Recreational tourism. International Thomas Business Press, USA

TBYGM (2004). Turizm Bakanlığı Yatırımlar Genel Müdürlüğü. Kurumlar Arası Yazışmalar

Topay M \& Memlük Y (2011). Rekreasyonel etkinlikler için uygun alan seçimine yönelik yeni bir yöntem yaklaşımı: Bartın-Uluyayla örneği, SDÜ Orman Fakültesi Dergisi 12: 141-147

Topay M (2002). Kırsal alanlarda gerçekleştirilecek rekreasyon - turizm aktiviteleri içın uygun alan seçiminde CBS kullanımı, Fatih Üniversitesi. http:// cbs2004.fatih.edu.tr/download/file432.pdf (Erişim tarihi: 14.04.2014)

Topay M (2003). Bartın-Uluyayla peyzaj özelliklerinin rekreasyon-turizm kullanımları açısından değerlendirilmesi üzerinde bir araştırma. Doktora Tezi, Ankara Üniversitesi, Fen Bilimleri Enstitüsü (Basılmamış), Ankara

Topay M (2007). The importance of climate for recreational planning of rural areas; casestudyof Muğla Province, Turkey, In: A Matzarakis, De Freitas C R \& Scott D (Eds), Developments in Tourism Climatology, Alexandroupolis, Greece, pp. 19-22

Türkoğlu M, Gövdere B \& Meydan Ç (2005). Isparta ili turizminin sorunları ve çözüm önerileri. SDÜ Sosyal Bilimler Enstitüsü Dergisi 1: 28-29

Yeşiltaş M \& Öztürk İ (2008). Bölgesel kalkınma çerçevesinde alternatif turizm faaliyetlerine yönelik bir değerlendirme: Sivas örneği. Ç. $\ddot{U}$. Iktisadi ve Idari Bilimler Dergisi 9(1): 1-18 